2. H. Budzikiewicz, C. Djerassi, and D. Williams, Interpretation of Mass Spectra of Organic Compounds [Russian translation], Moscow, p. 303, 1966.

3. A. Samatov, S. T. Akramov, and S. Yu. Yunusov, KhPS [Chemistry of Natural Compounds], 3, $182,1967$.

7 June 1968

Institute of the Chemistry of Plant Substances, AS UzSSR

UDC $547.944 / 945$

\title{
STRUCTURE OF THALSIMIDINE
}

S. Kh. Maekh, Z. F. Ismailov, and S. Yu. Yunusov

Khimiya Primodnykh Soedinenii, Vol. 4, No. 6, pp. 393-394, 1968

We have isolated thalsimidine $\mathrm{C}_{37} \mathrm{H}_{38} \mathrm{~N}_{2} \mathrm{O}_{7}$ (I) from the epigeal part of Thalictrum simplex $\mathrm{L}$. [1]. The products of the Hofmann degradation of N,O-dimethyldihydro-(I) were shown by TLC to be identical with the corresponding hernandezine derivatives. The methylation of thalsimidine with diazomethane gave thalsimine (II). Consequently, thalsimidine (I) is demethylthalsimine.

\begin{tabular}{|c|c|c|c|c|c|c|c|c|c|}
\hline \multirow{2}{*}{$\begin{array}{l}\text { Sub- } \\
\text { stance }\end{array}$} & \multicolumn{9}{|c|}{$\mathrm{m} / \mathrm{e}$ (relative intensity, $\%$ ) } \\
\hline & $M^{+}$ & $M++$ & $(M-1)^{+}$ & $(M-15)^{+}$ & $(M-31)+$ & $\mathbf{a}$ & b & c & d \\
\hline $\begin{array}{l}\text { (I) } \\
\text { (III) }\end{array}$ & $\begin{array}{l}622(100) \\
636(100)\end{array}$ & $\begin{array}{l}311(28) \\
318(24)\end{array}$ & $\begin{array}{l}621(60) \\
635(64)\end{array}$ & $\begin{array}{l}607(56) \\
621(51)\end{array}$ & $\begin{array}{l}591(20) \\
605(17)\end{array}$ & $\begin{array}{l}485(10 \\
499(11\end{array}$ & $\begin{array}{l}221(8) \\
235(12)\end{array}$ & $\begin{array}{l}190(10) \\
190(11)\end{array}$ & $\begin{array}{l}175(6) \\
175(5)\end{array}$ \\
\hline
\end{tabular}

The presence in the mass spectrum of (I) of an ion with $\mathrm{m} / \mathrm{e} 485$ (fragment $\mathrm{a}, \mathrm{R}=\mathrm{H}$ ) shows that the hydroxy group in the substance is present in the isoquinoline part of the molecule. The mass spectra of (I) and (II) can be judged from the figures in the table (the spectra were taken on a Hitachi RMU -6DC instrument).

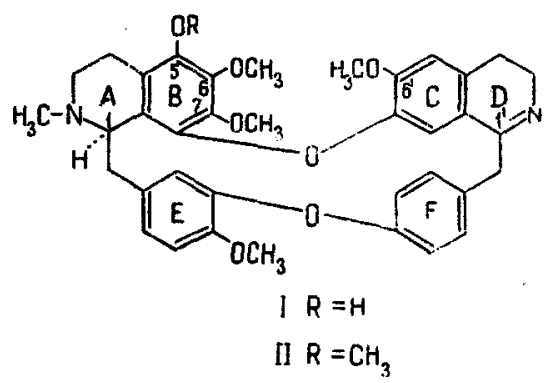

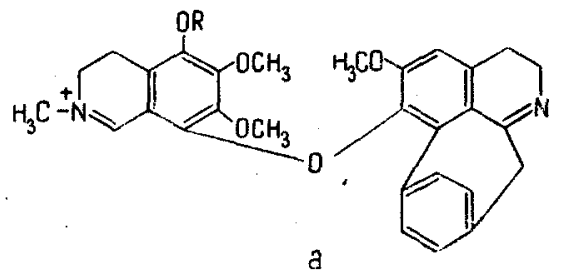

Fragment $b$ is formed from $(M)^{+}$by the loss of the successive rings $C, D, E$, and $F$. The splitting off of OCH from the ion $b$ leads to the production of fragment $c$. The ion with $\mathrm{m} / \mathrm{e} 175$ (fragment $\mathrm{d}$ ) is formed by the loss by the molecular ion of the rings A, B, E, and $\mathrm{F}$ with closure of the ether bridge in position 1' [2]. By decomposing substance (l) with sodium in liquid ammonia, we obtained monomolecular compounds. If, in the bisbenzylisoquinoline bases the hydroxy group is in the ortho position to the ether bridge, the rupture of this bridge does not take place [3]. Therefore, there is no hydroxy group in positions $6^{\prime}$ and 7 of $\mathrm{c}(\mathrm{I})$. On the basis of a positive Millon reaction [4], positions 6 and $6^{\prime}$ are also excluded. Thus, position 5 remains the most probable one for the hydroxy group and the most probable structure for thalsimidine is (I) with the $\mathrm{L}$-configuration at $\mathrm{C}-1$.

\section{REFERENCES}

1. S. Kh. Maekh, Z. F. Ismailov, and S. Yu. Yunusov, KhPS [Chemistry of Natural Compounds], 4, $138,1968$.

2. J. Baldas and Q. N. Porter, Tetrah. Let., $2059,1966$.

3. V. Inubushi, J. Pharm. Soc. Japan, 72, 220, 1952; C. A., 6429, 1953.

4. H, King, J. Chem. Soc., 1472, 1937; 737, 1940. 